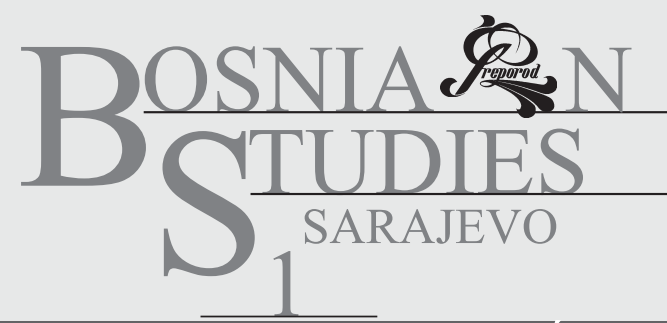

*AMER OSMIC

"Bosnianness Or Anti-Bosnianness, That Is the Question"

A Discourse On Bosnianess by Senadin Lavić

UDC: $323.1(497.6)$

DOI 10.47999/bos.2021.5.1.84-87

Book review

pages $82-85$

* Faculty of Political Sciences, University of Sarajevo 
"Bosnianness Or Anti-Bosnianness, That Is the Question" A Discourse On Bosnianess by Senadin Lavić, Faculty of Political Sciences (2020)

\section{(Book review)}

The book, A Discourse On Bosnianness, by the author Senadin Lavić, analyzes and with methodological precision, positions the concepts of nations and states on the one hand, and ethnicity and people on the other. The book is divided into twelve chapters, where Lavić begins with a prolegomenon for the Bosnian nation and later analyzes its identity, history and emblems. In the following chapters, Lavić then analyzes Bosniak folk cultural forms and religious consciousness and introduces them to the discourse on the Bosniak question. In a chapter on ethnicism and "tribes" in agony, the lack of rational speech about the nation and the national ideal, is precisely identified, noting that it is reduced to ethnicism, i.e. ethnopolitics in social and political communities. Analyzing certain chapters more specifically, we notice that Bosnia, Bosnian emblems and all kinds of identity forms do not exclude any other identity that a Bosnian has or can have, giving a clear explanation of what they are, and how to perceive notions having their hierarchy, while not imposing any form of identity on anyone. Lavić correlates the notions of nation, people, ethnicity, identity and contextualizes them sociologically, methodologically, and epistemologically with regard to today's $\mathrm{B} \& \mathrm{H}$. He considers scientifically relevant theoretical positions and understandings of these notions in scientific discourse. A Discourse On Bosnianess defines concepts such as ethnicism, religious consciousness, and ethnopolitics, with clear theoretical, empirical constructs and deconstructs the meaning of these terms in order to indicate the existence of Bosnian national identity, which includes national, ethnic, religious, and all other identities that an individual may have, as well as destigmatizing the Bosnian identity as one that has an absolutist meaning and, according to quantitative indicators belongs to the people who are the most numerous in the state of Bosnia.

Lavić follows the "red thread" of Bosnian identity as being both plural in construction and common to those who are tied to the state of $\mathrm{B} \& \mathrm{H}$. The destructive ethnopolitics that continuously act on the creation of ideologically determined understandings of the existence of the "three nations" in Bosnia, must be opposed by understanding and searching through scientific argumentation of a both theoretically and empirically democratic nation or state.

Lavić sees the main reasons for the inferior position of the Bosnian nation in the post-Dayton reality of B\&H in the ideological "set of circumstances" that "began to act" much earlier, by completely marginalizing and "silencing" all those who 
scientifically and methodically argued the existence of the Bosnian nation, in the context of the Balkans and European processes. Thus, in the very introduction to A Discourse On Bosnianess, Lavić states that; "Bosnian identity is based on the freedom and dignity of the individual man, which is not omnipresent but is particular, individual, and partial" and is an idea that must become universal for all Bosnians. The notion of the Bosnian nation or Bosnianess, is the only and logical thing in the reality of $\mathrm{B} \& \mathrm{H}$, that being acceptable and exceeding ideological understandings should be treated as an "inclusive concept of life". Bosnia and the Bosnian identity, which can be scientifically defined, have been continuously and systematically suppressed and reduced to the "stereotype of a bridge and a geographical point of contact of the worlds" for the "higher goals" of previous systems. Today, many "Balkan centers of power" speak of Bosnia as an "innovation", something that has been drawing its right to exist only in the last 25 years, while ignoring scientific indicators that clearly and precisely speak of the historical significance and existence of Bosnian identity, which is now deliberately amputated from Bosnian social life. This diminishes and systematically undermines the significance of Bosnia and Bosnianess in the historical and political construct of the Balkan nations. This marginalization is best seen in bypassing or "forbidding" the use of Bosnian symbols in the form of speech, words, terms, or names under the guise that Bosnian symbols undermine the "multiethnicity and multiculturalism" of today's Bosnian state, done with the goal of making the expansion and even the existence, of Bosnia's political space impossible.

In $A$ Discourse On Bosnianess, Lavić highlights and subsequently analyzes the stated ideological matrix that prevents the notion of Bosnianess, with all its identity characteristics and limited plurality, from being established as the national identity of all citizens of B\&H. Of course, the conservative consciousness and the continuous suppression of Bosnian national thought, by the dominant ethno-territorialist approach contribute to this, which equates the notion of nation (which is much broader), with the notion of ethnicity and even religion. Lavić states, "The Balkan habit is to associate the definition of people and identity with religion, and then to not distinguish cultural identity (ethnos or some national group) from legal-political identity (nation or community of equal and free citizens)." On the other hand, advocating for the scientific engagement with the nation implies going beyond political myths and common-sense struggles over concepts. Here, of course, the goal is to not give a final answer about how the state of a society in which all the criteria of logical thinking were destroyed, knowledge no longer has value, and science is measured by ideological criteria of politics or religion. Rather, it is clear that Lavić's epistemological-methodological approach to understanding the concepts of nation, people and ethnicity, differs in many ways from the conservative and outdated "absolute scientific truths" established in this area, because it uses logical insight and modern and contextualized scientific ar-

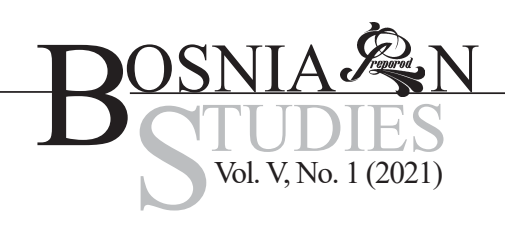


gumentation that destroy the quasi-argument which promulgates the idea of three nations in $\mathrm{B} \& \mathrm{H}$. According to the above, I warmly recommend everyone to analyze the flow of argumentation in this book and make their judgment about the notion of Bosnia and the Bosnian nation, which are terms that are not against, but go along with the Bosnian nation and refer to the multitude of identities that an individual may have, including their ethnic, folk, or religious identity. 